\title{
Cadaver shows stir controversy
}

Published at www.cmaj.ca on Sept. 2

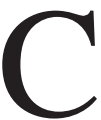

oating skinless human cadavers in liquid plastic and charging humans still living in their skin an admission fee to take a look has become a lucrative business. But all is not well in the land of corporate corpse display. Critics say some human cadaver exhibits do not obtain consent from either the deceased people on display or their families. These criticisms are getting noticed, and some areas are banning these very popular shows.

Cadaver exhibits are not allowed, for instance, in San Francisco, California, or in the state of Hawaii. One of the latest bans was instituted in July by the city council of Seattle, Washington.

The Seattle ban stems from a complaint filed in United States District Court in 2006 by Charlette LeFevre and Philip Lipson, who run the Seattle Museum of the Mysteries. In 2004, Lipson learned that "Bodies ... The Exhibition," a show run by Atlanta, Georgia-based Premier Exhibitions, would be visiting Seattle in 2006. Contemplating having a cutting-edge educational display for his museum, Lipson researched the "Bodies" show and was dismayed to discover that the cadavers come from unclaimed bodies in China.

"These exhibits fly into a city, do multi-million-dollar marketing and give the impression everything has been checked out, endorsed and is educational when in fact they know they do not have any consent papers and even the death certificates," Lipson writes in an email.

The "Bodies" exhibition's website states that the cadavers are "persons who lived in China and died from natural causes. After the bodies were unclaimed at death, pursuant to Chinese law, they were ultimately delivered to a medical school for education and research. Where known, information about the identities, medical histories and causes of death is kept strictly confidential."

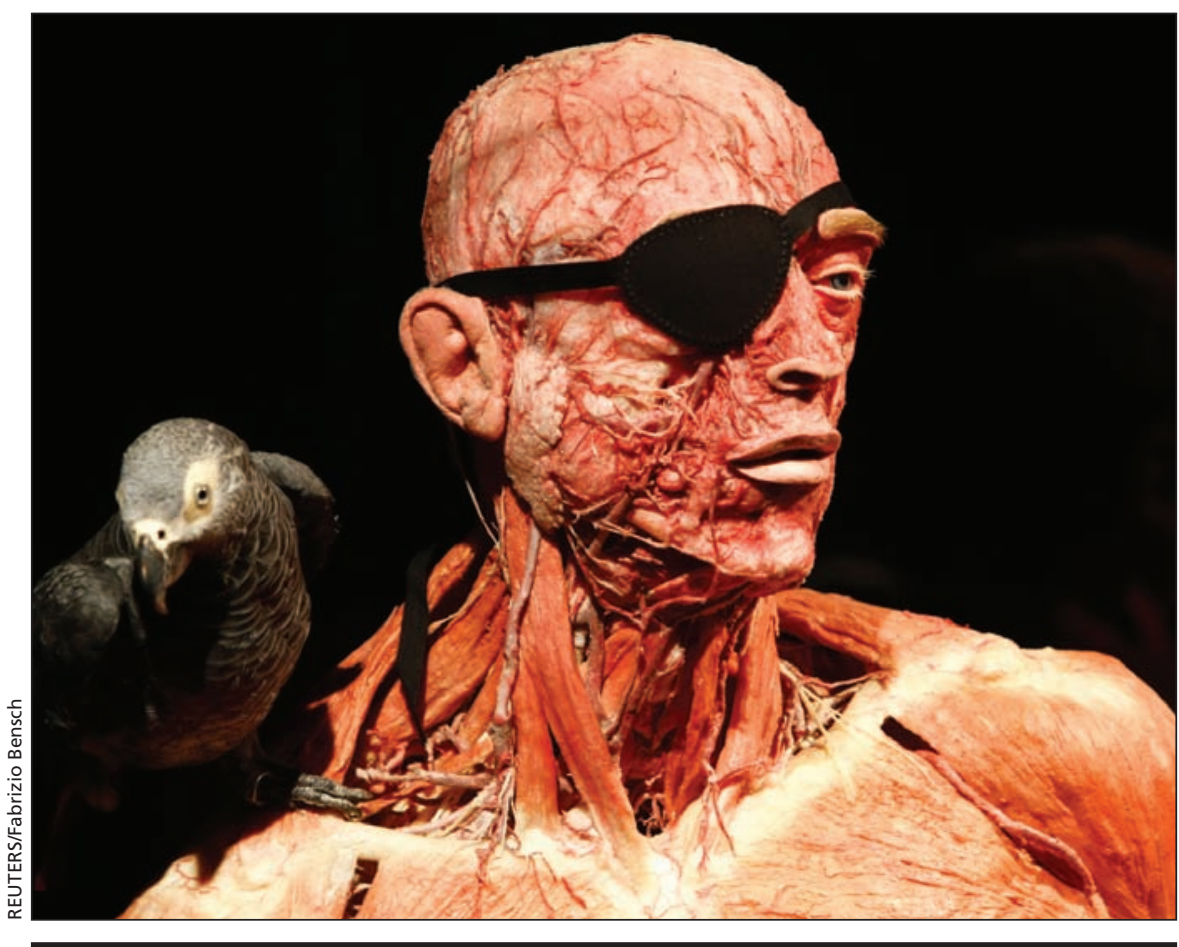

A plastinated human body that was part of anatomist Gunther von Hagens "Body Worlds" exhibition in Berlin, Germany.

Lipson's public opposition to the "Bodies" exhibition gained praise from Seattle's Chinese community and Falun Gong groups, but stirred anger among some of the general public. This should come as no surprise, of course, considering how popular travelling corpse shows have become. There are about a dozen such exhibitions, which travel the world and have been seen by tens of millions of people. When the California Science Centre hosted "Body Worlds," there were lineups at 3:30 a.m. on closing weekend, when the exhibit was open 24 hours a day.

The shows may be popular and educational, says Lipson, but that doesn't mean they are ethical. "We don't know of any culture that takes bodies from another country and exhibits them against their cultural belief (it then becomes desecration) for profit," writes Lipson. "Even the shows that claim consent, there is no third-party verification and it provides a slippery slope for crime, early executions and a black market in bodies. If you think about it, this is the very reason why graverobbing laws were written."

According to bioethicist Laurie Zoloth, however, shows that display human corpses are not unethical as long as consent has been obtained. Six years ago, Zoloth, the director of the Center for Bioethics, Science and Society at Northwestern University in Illinois, sat on a committee of bioethicists and religious leaders that allowed the Chicago Museum of Science and Industry to host a show similar to the "Bodies" exhibit. The difference, however, was that the bodies in that exhibit belonged to people who had consented to their remains being put on public display.

"I find this astonishing, but that is beside the point," Zoloth writes in an email. "We allow people to display their bodies in ways I find silly, offensive or absurd, on the streets of any major city. This would not be how I would advise 
anyone to relate to their death, but really, it is not an ethical issue if they consider the idea, find it appealing, sign a consent and then, after all, are dead."

But if the bodies are unclaimed, as in the "Bodies" show, that is another matter. "A body of a lost, anonymous person is the responsibility of our community to honor if we cannot find her family, and must be buried properly, a law that emerges from the shared scriptural traditions of many religions," writes Zoloth.

Even if people do consent to having their remains put on public display, there may still be ethical concerns, says
Kerry Bowman, a bioethicist at the University of Toronto Joint Centre for Bioethics in Ontario. Last year, Bowman attended a cadaver exhibition, where he saw bodies posed as hockey players, gymnasts and in positions that were vaguely sexual. If people consent to having their bodies used for educational purposes only, he says, these types of displays cross a line.

"I found it a lot more disturbing that I thought I would," says Bowman. "There were aspects that troubled me, and one of the strong ones was if this was education or entertainment."
Some parts of the exhibition, though, were clearly educational, Bowman says, such as a display contrasting a healthy lung to that of a smoker. "That was a powerful image," he says. Still, no matter the value of shows that display human remains, says Bowman, it all comes down to informed, voluntary and capable consent. "From an ethical point of view, the educational merit of something will never trump individual consent." - Roger Collier, CMAJ

DOI:10.1503/cmaj.109-3351 